\title{
PENGARUH KEPEMIMPINAN DAN MOTIVASI KERJA TERHADAP KINERJA PEGAWAI BBTA3-BPPT KAWASAN PUSPIPTEK SETU TANGERANG SELATAN
}

\author{
Didi Sunardi \\ Fakultas Ekonomi, Universitas Pamulang \\ Email: dosen007240@unpam.ac.id
}

\begin{abstract}
Purpose. This study aims to determine the influence of leadership and motivation on the performance of employees of BBTA3-BPPT Kawasan Puspiptek Setu, South Tangerang. Method. The research.

Methods. used in this study is an associative method and data collection using a questionnaire technique. This study used a saturated sample with 76 respondents. The method of data analysis was the validity test, reliability test, multiple linear regression equations, correlation coefficient, determination coefficient, and significance test.

Findings. The results showed a leadership correlation of 0.730 and motivation of 0.646 , which means that leadership and motivation have a very strong level of influence on employee performance. In the multiple linear regression equation, $Y=4.339+0.561+0.253$ $X 2$, which means that if the X1 variable is increased by 1 unit, then the $Y$ variable increases by 0.561 units at the constant 4.339, and if the X2 variable is increased by 1 unit, then the $Y$ variable increases by 0.253 units at the constant 4.339. The coefficient of determination $56.8 \%$ indicates that the amount of contribution of the independent variables (leadership and motivation) in an effort to improve employee performance, while the remaining $43.2 \%$ is influenced by other factors not examined in this study. After the hypothetical test was carried out, simultaneously there was a significant influence between leadership and motivation on the performance of BBTA3-BPPT employees, this can be seen in F count> F table or 51.649> 3.18..
\end{abstract}

Implication. Leaders at BBTA3 should always pay attention and provide motivation for employees to remain enthusiastic, on time and productive at work so that they can support employee performance in achieving goals with quality and on time in completing work.

Keywords. Leadership, Motivation, Performance

\begin{abstract}
ABSTRAK
Tujuan. Penelitian ini bertujuan untuk mengetahui pengaruh kepemimpinan dan motivasi terhadap kinerja pegawai BBTA3-BPPT Kawasan Puspiptek Setu Tangerang Selatan.

Metode. Metode penelitian yang digunakan dalam penelitian adalah data yang bersifat Metode penelitian yang dipergunakan dalam penelitian ini adalah metode asosiatif dan pengumpulan data dengan teknik kuesioner. Penelitian ini menggunakan sampel jenuh dengan responden sebanyak 76. Metode analisis data dengan uji validitas, uji reliabilitas, persamaan regresi linier berganda, koefisien kolerasi, koefisien determinasi, dan uji signifikansi.
\end{abstract}

Hasil. Hasil penelitian menunjukkan korelasi kepemimpinan sebesar 0,730 dan Motivasi sebesar 0,646 yang artinya kepemimpinan dan motivasi mempunyai tingkat pengaruh 
yang sangat kuat terhadap kinerja pegawai karyawan. Dalam persamaan regresi linier berganda di dapat $Y=4,339+0,561+0,253 X 2$ yang artinya apabila variabel X1 dinaikan 1 satuan, maka variabel $Y$ naik sebesar 0,561 satuan pada konstanta 4,339, dan apabila variabel X2 dinaikan 1 satuan, maka variabel Y naik sebesar 0,253 satuan pada konstanta 4,339. Nilai koefisien determinasi 56,8\% menunjukan bahwa besarnya konstribusi dari variabel bebas (Kepemimpinan dan Motivasi) dalam upaya meningkatkan kinerja pegawai, sedangkan sisanya $43,2 \%$ dipengaruhi oleh faktor lain yang tidak diteliti dalam penelitian ini. Setelah dilakukan uji hipotetsis, secara simultan terdapat pengaruh yang signifikan antara kepemimpinan dan motivasi terhadap kinerja pegawai BBTA3-BPPT, hal ini terlihat pada $\mathrm{F}$ hitung $>\mathrm{F}$ tabel atau 51,649 > 3,18.

Implikasi. Pimpinan di BBTA3 hendaknya selalu memperhatikan dan memberikan motivasi untuk pegawainya supay tetap semangat, tepat waktu dan produktif dalam bekerja sehingga dapat menunjang kinerja pegawai dalam pencapaian tujuan dengan kualitas dan tepat waktu dalam penyelesaian pekerjaan.

Kata Kunci. Kepemimpinan, Motivasi, Kinerja

\section{Pendahuluan}

Kepemimpinan memiliki pengertian yang agak luas dibandingkan dengan manajemen. Manajemen merupakan jenis pemikiran yang khusus dari kepemimpinan di dalam usahanya mencapai tujuan organisasi. Kepemimpinan tidak harus dibatasi oleh aturan-aturan atau tata krama birokrasi. Kepemimpinan tidak harus diikat dalam suatu organisasi tersebut. Melainkan kepemimpinan bisa terjadi dimana saja, asalkan seseorang menunjukkan kemampuannya mempengaruhi perilaku orang-orang lain ke arah tercapainya suatu tujuan tertentu. Maka dapat saja terjadi seorang manajer berperilaku sebagai seorang pemimpin, asalkan dia mampu mempengaruhi perilaku orang-orang lain untuk mencapai tujuan tertentu. Tetapi seorang pemimpin belum tentu harus menyandang jabatan manajer untuk mempengaruhi perilaku orang lain. Dengan kata lain, seorang leader atau pemimpin belum tentu seorang manajer, tetapi seorang manajer bisa berperilaku sebagai seorang leader atau pemimpin. (Thoha, 2017).

Kepemimpinan adalah sebagai penggerak dalam melaksanakan tugas-tugasanya. Kepemimpinan mempunyai tugas sebagai penggerak, dinamisator dan koordinator dari sumber daya manusia, sumber daya alam, semua dana, dan sasaran yang disiapkan oleh sekumpulan manusia yang berorganisasi. (Kartono, 2016).

Balai Besar Teknologi Aerodinamika, Aeroelastika, dan Aeroakustika (BBTA3) adalah unit kerja di bawah Badan Pengkajian dan Penerapan Teknologi (BPPT), dalam menjalankan tugasnya mempunyai tugas sebagai: 1). Penerapan teknologi aerodinamika, aeroelastika dan aeroakustika, 2). Pelayanan pengujian teknologi aerodinamika, aeroelastika dan aeroakustika, 3). Pelaksanaan urusan ketatausahaan, perencanaan, keuangan, sumber daya manusia, rumah tangga dan pelaporannya. BBTA3 memberikan pelayanan pengujian benda-benda yang berhubungan dengan udara contohnya: pesawat terbang, jembatan bentang panjang, gedung tinggi. Dalam perkembangnya BBTA3 telah melakukan pengujian pesawat milik indonesia atau luar negeri dan telah melakukan beberapa pegujian jembatan panjang di seluruh indonesia. Untuk hal tersebut BBTA3 dalam pelayanan pengujiannya sangat memerlukan kepemimpinan yang dapat menggerakan seluruh sumber daya yang ada dalam pencapaian tujuan dari BBTA3 dan pegawainya. Pimpinan yang ada di tempat penelitian merupakan pimpinan birokrasi yang diangkat berdasarkan peraturan yang ada, dalam menjalankan tugas tentunya sudah ada aturan dan kebijakan yang dilakukan, sehingga kurangnya improvisasi dalam menjalankan tugasnya. 
Tabel 1. Data Kepemimpinan (BBTA3)

\begin{tabular}{|c|l|l|l|}
\hline No & \multicolumn{1}{|c|}{ Indikator } & \multicolumn{1}{|c|}{ Kondisi } & \multicolumn{1}{|c|}{ Keterangan } \\
\hline 1 & Disiplin & $\begin{array}{l}\text { Pemimpin tidak ada di } \\
\text { kantor. }\end{array}$ & $\begin{array}{l}\text { Beberapa pemimpin meninggalkan } \\
\text { kantor tanpa keterangan pada jam } \\
\text { operasional. }\end{array}$ \\
\hline 2 & Kerjasama & $\begin{array}{l}\text { Kurang mampu bekerja } \\
\text { sama dengan bawahan. }\end{array}$ & $\begin{array}{l}\text { Pemimpin kurang berkomunikasi } \\
\text { dengan dalam } \\
\text { menyelesaikan pekerjaan. }\end{array}$ \\
\hline 3 & Kreatif & $\begin{array}{l}\text { Pemimpin tidak dapat } \\
\text { memberikan ide-ide baru. }\end{array}$ & $\begin{array}{l}\text { Pemimpin belum mampu } \\
\text { menciptakan perubahan-perubahan } \\
\text { yang signifikan karena pemimpin } \\
\text { masih dibatasi dengan peraturan } \\
\text { yang sudah ada. }\end{array}$ \\
\hline 4 & $\begin{array}{l}\text { Merealisasikan } \\
\text { Program }\end{array}$ & $\begin{array}{l}\text { Pemimpin belum mampu } \\
\text { merealisasikan beberapa } \\
\text { program. }\end{array}$ & $\begin{array}{l}\text { Ada program pengujian layanan } \\
\text { teknologi yang sudah di program } \\
\text { akan tetapi tidak semua } \\
\text { terealisasikan. }\end{array}$ \\
\hline
\end{tabular}

Sumber : BBTA3 (2020)

Selain kepemimpinan, motivasi merupakan hal yang sangat penting untuk diperhatikan oleh pihak manajemen bila mereka menginginkan setiap pegawai dapat memberikan kontribusi positif terhadap pencapaian tujuan perusahaan, karena dengan motivasi seorang pegawai akan memiliki semangat yang tinggi dalam melaksanakan tugas yang diberikan kepadanya. Tanpa motivasi, seorang pegawai tidak dapat memenuhi tugasnya sesuai standar. Sekalian seorang pegawai memiliki kemampuan operasional yang baik bila tidak memiliki motivasi dalam bekerja, hasil kerja dari pekerjaanya tidak akan memuaskan. Dengan demikian motivasi merupakan faktor yang sangat penting dalam meningkatkan kinerja pegawai karena motivasi sangat berpengaruh dan positif dalam meningkatkan kinerja pegawai

Menurut Hasibuan (2016:110), Motivasi adalah suatu rangsangan keinginan dan daya penggerak kemauan bekerja seseorang karena setiap motivasi mempunyai tujuan tertentu yang ingin dicapai. Adapun menurut Siagian (2015:85), mengatakan bahwa motivasi adalah keadaan kejiwaan yang mendorong, mengaktifkan atau menggerakan dan motivasi itulah yang mengarahkan dan menyalurkan perilaku, sikap dan tindak tanduk seseorang yang selalu dikaitkan dengan pencapaian tujuan, baik tujuan organisasi maupun tujuan pribadi masingmasing anggota organisasi. Motivasi merupakan akibat dari interaksi seseorang dengan situasi tertentu dibandingkan dengan orang lain yang sama. Bahkan, seseorang akan menunjukkan dorongan tertentu dalam waktu yang berlainan pula.

Bentuk pemberian motivasi kepada pegawainya, yaitu dengan memenuhi keinginankeinginan pegawai antara lain: gaji atau upah yang baik, pekerjaan yang aman, suasana kerja yang nyaman untuk pegawai, pemberian penghargaan atas prestasi kerja yang dilakukan, serta pimpinan yang adil dan bijaksana dalam mengambil keputusan. Karena gaji atau upah sangat diperlukan untuk memacu kinerja para pegawai agar selalu pada tingkat kerja yang maksimal dan sesuai dengan kemampuan masing-masing.

Sistem penggajian yang ada di tempat penelitian semuanya sudah diatur dalam peraturan pemerintah, dan tidak ada lagi tambahan penghasilan lainnya. Sehingga untuk meningkatkan kinerja dengan memberikan motivasi melalui pemberian penghasilan lainnya atau honor sangat sulit dilakukan. Apabila di perusahaan swasta ada pemberian bonus setiap akhir tahun, atau pemberian penghargaan kepada pegawai yang berprestasi, namun ditempat penelitian ini sulit untuk dilakukan dan tidak pernah ada bonus tahunan. 
Tabel 2. Data Motivasi Kerja (BBTA3)

\begin{tabular}{|c|c|c|c|c|}
\hline \multirow{2}{*}{ Indikator } & Jenis Motivasi & \multicolumn{3}{|c|}{ Tahun } \\
\cline { 3 - 5 } $\begin{array}{c}\text { Kebutuhan } \\
\text { Fisiologis }\end{array}$ & $\begin{array}{c}\text { Fasilitas } \\
\text { Kepemilikan } \\
\text { Perumahan }\end{array}$ & Tidak Ada & Ada & Ada19 \\
\hline $\begin{array}{c}\text { Kebutuhan Rasa } \\
\text { Aman }\end{array}$ & $\begin{array}{c}\text { Asuransi } \\
\text { Kesehatan }\end{array}$ & $\begin{array}{c}\text { BPJS Kesehatan } \\
\text { (Ada) }\end{array}$ & $\begin{array}{c}\text { BPJS } \\
\text { Kesehatan } \\
\text { (Ada) }\end{array}$ & $\begin{array}{c}\text { KesJS } \\
\text { Kehatan } \\
\text { (Ada) }\end{array}$ \\
\cline { 2 - 5 } & $\begin{array}{c}\text { Asuransi } \\
\text { Kecelakaan }\end{array}$ & $\begin{array}{c}\text { BPJS Ketenaga } \\
\text { kerjaan (Ada) }\end{array}$ & $\begin{array}{c}\text { BPJS Ketenaga } \\
\text { kerjaan (Ada) }\end{array}$ & $\begin{array}{c}\text { BPJS Ketenaga } \\
\text { kerjaan (Ada) }\end{array}$ \\
\cline { 2 - 5 } & Pesangon & Tidak Ada & Tidak Ada & Tidak Ada \\
\hline $\begin{array}{c}\text { Kebutuhan } \\
\text { Penghargaan }\end{array}$ & Uang Makan & Rp.20.000/hari & Rp.30.000/hari & Rp.40.000/hari \\
\cline { 2 - 5 } & Uang Transport & Tidak Ada & Tidak Ada & Tidak Ada \\
\hline Kebutuhan Sosial & Gathering & Tidak Ada & Tidak Ada & Tidak Ada \\
\hline Aktualisasi Diri & Promosi Jabatan & Tidak Ada & Tidak Ada & Ada \\
\cline { 2 - 5 } & $\begin{array}{c}\text { Tugas Belajar } \\
\text { Lanjut }\end{array}$ & Tidak Ada & Ada & Ada \\
\hline
\end{tabular}

Sumber : BBTA3 (2020)

Dari tabel 1.2 di atas dapat disimpulkan bahwa observasi pada pegawai di BBTA3 dengan indikator kebutuhan rasa aman dan sosial belum optimal. Hal ini dapat dilihat pada tahun 2017-2019 tidak ada pesangon dan gathering dari perusahaan. Apabila ini tidak diberikan kepada pegawai maka akan menghambat penyelesaian pekerjaan dan penurunan kinerja pegawai. Pegawai yang memiliki motivasi yang tinggi akan membuat perusahaan menjadi lebih baik. Loyalitas dan semangat kerja dapat dilihat dari mereka yang merasa senang ataupun nyaman dengan pekerjaannya, sehingga kinerja pegawai akan optimal serta visi dan misi perusahaan dapat tercapai dengan baik.

Menurut Mangkunegara (2013:67), kinerja adalah hasil kerja secara kualitas dan kuantitas yang dicapai oleh seorang karyawan dalam melaksanakan tugasnya sesuai dengan tanggung jawab yang diberikan kepadanya. Sedangkan Sedarmayanti (2010:176), mendefinisikan kinerja sebagai hasil kerja yang dapat dicapai oleh seseorang atau sekelompok orang dalam suatu organisasi, sesuai dengan wewenang dan tanggung jawab masing-masing dalam upaya mencapai tujuan organisasi bersangkutan secara legal, tidak melanggar hukum dan sesuai dengan norma maupun etika. Kinerja merupakan suatu hasil kerja yang dihasilkan oleh seorang pegawai diartikan untuk mencapai tujuan yang diharapkan. Permasalahan yang ada pada BBTA3 adalah tingkat absensi pegawai yang masih belum optimal. Berikut ini dapat digambarkan kinerja pegawai, berdasarkan hasil studi dokumentasi.

Tabel 3. Data Kinerja Pegawai BBTA3

\begin{tabular}{|c|c|c|c|c|}
\hline Tahun & $\begin{array}{c}\text { Target Layanan } \\
\text { Teknologi }\end{array}$ & Realisasi & $\%$ & Keterangan \\
\hline 2017 & $\begin{array}{c}20 \text { Layanan } \\
\text { Teknologi }\end{array}$ & $\begin{array}{c}16 \text { Layanan } \\
\text { Teknologi }\end{array}$ & $80 \%$ & \multirow{3}{*}{$\begin{array}{l}\text { Layanan teknologi aerodinamika } \\
\text { adalah Pengujian moment pesawat. } \\
\text { Layanan teknologi aeroelastika } \\
\text { adalah } \text { Pengujian jembatan } \\
\text { bentang panjang. Layanan } \\
\text { teknologi aeroakustika adalah } \\
\text { Pengujian kebisingan gedung, } \\
\text { kendaraan (MRT dan LRT). }\end{array}$} \\
\hline 2018 & $\begin{array}{l}9 \text { Layanan } \\
\text { Teknologi }\end{array}$ & $\begin{array}{c}25 \text { Layanan } \\
\text { Teknologi }\end{array}$ & $278 \%$ & \\
\hline 2019 & $\begin{array}{c}16 \text { Layanan } \\
\text { Teknologi }\end{array}$ & $\begin{array}{c}12 \text { Layanan } \\
\text { Teknologi }\end{array}$ & $75 \%$ & \\
\hline
\end{tabular}

Sumber : BBTA3 (2020). 
Berdasarkan Tabel 1.4 di atas, dapat diambil kesimpulan bahwa persentase tingkat pencapaian kinerja pegawai di BBTA3 belum optimal karena pada tahun 2019 mengalami penurunan dalam layanan pengujian suatu teknologi, sehingga kinerja pegawai belum berjalan dengan baik.

Berdasarkan latar belakang di atas peniliti tertarik untuk melakukan penelitian dengan judul "Pengaruh Kepemimpinan Dan Motivasi Kerja Terhadap Kinerja Pegawai Balai Besar Teknologi Aerodinamika, Aeroelastika Dan Aerokustika (BBTA3) BPPT Di Gedung 240 Kawasan Puspiptek Setu Tangerang Selatan"

\section{Kajian Pustaka dan Hipotesis}

Kepemimpinan. Kepemimpinan merupakan bentuk strategi atau teori memimpin yang tentunya dilakukan oleh orang yang biasa kita sebut sebagai pemimpin. Pemimpin adalah seseorang dengan wewenang kepemimpinannya mengarahkan bawahannya untuk mengerjakan sebagian dari pekerjaannya dalam mencapai tujuan. Sedangkan Rivai (2017:2), menyatakan gaya kepemimpinan adalah sekumpulan ciri yang digunakan pimpinan untuk memengaruhi bawahan agar sasaran organisasi tercapai atau dapat pula dikatakan bahwa gaya kepemimpinan adalah pola perilaku dan strategi yang disukai dan sering diterapkan oleh seorang pemimpin. Gaya kepemimpinan yang menunjukkan, secara langsung maupun tidak langsung, tentang keyakinan seorang pimpinan terhadap kemampuan bawahannya. Artinya gaya kepemimpinan adalah perilaku dan strategi, sebagai hasil kombinasi dari falsafah, keterampilan, sifat, sikap, yang sering diterapkan seorang pemimpin ketika ia mencoba memengaruhi kinerja bawahannya.

Motivasi Kerja. Motivasi merupakan suatu dorongan kebutuhan dalam diri pegawai yang perlu dipenuhi agar pegawai tersebut dapat menyesuaikan diri terhadap lingkungannya, sedangkan motivasi adalah kondisi yang menggerakan pegawai agar mampu mencapai tujuan dari motivasinya. Menurut Hasibuan dalam Sutrisno (2016:110), Motivasi adalah suatu rangsangan keinginan dan daya penggerak kemauan bekerja seseorang karena setiap motivasi mempunyai tujuan tertentu yang ingin dicapai. Motivasi merupakan akibat dari interaksi seseorang dengan situasi tertentu dibandingkan dengan orang lain yang sama. Bahkan, seseorang akan menunjukkan dorongan tertentu dalam waktu yang berlainan pula.

Kinerja Pegawai. Kinerja sebagai hasil kerja yang dapat dicapai oleh seseorang atau sekelompok orang dalam suatu organisasi, sesuai dengan wewenang dan tanggung jawab masing-masing dalam upaya mencapai tujuan organisasi bersangkutan secara legal, tidak melanggar hukum dan sesuai dengan norma maupun etika. Menurut Mangkunegara (2013:67), Kinerja adalah hasil kerja secara kualitas dan kuantitas yang dicapai oleh seorang karyawan dalam melaksanakan tugasnya sesuai dengan tanggung jawab yang diberikan kepadanya.

\section{Hipotesis}

H1. Kepemimpinan berpengaruh signifikan terhadap kinerja Pegawai BBTA3

H2. Motivasi berpengaruh terhadap kinerja Pegawai BBTA3

H3. Kepemimpinan dan motivasi kerja berpengaruh terhadap kinerja Pegawai BBTA3 secara simultan

\section{Metode Penelitian}

Jenis penelitian ini adalah asosiatif, menurut Sugiyono (2017:44) yaitu "Penelitian yang bertujuan untuk mengetahui pengaruh atau hubungan antara dua variabel atau lebih". Dengan demikian penelitian asosiatif ini dapat dibangun suatu teori yang berfungsi untuk menjelaskan, meramalkan dan mengontrol suatu gejala. Dalam penelitian populasinya adalah pegawai BBTA3-BPPT. Sementara sampel yang digunakan adalah seluruh pegawai BBTA3BPPT yang berjumlah 76 orang. 


\section{Uji Instrumen Penelitian}

Dalam suatu penelitian, data mempunyai kedudukan yang sangat penting. Hal ini dikarenakan data merupakan penggambaran variabel yang diteliti dan berfungsi sebagai alat pembuktian hipotesis. Valid atau tidaknya data sangat menentukan kualitas dari data tersebut. Hal ini tergantung instrumen yang digunakan apakah sudah memenuhi asas validitas dan reliabilitas. Adapun dalam pengujian instrumen ini digunakan 2 (dua) pengujian yaitu validitas dan reliabilitas.

\section{Uji Asumsi Klasik}

Uji asumsi klasik digunakan untuk mengetahui ketepatan sebuah data. Menurut Santoso (2015:342) berpendapat "Sebuah model regresi akan digunakan untuk melakukan peramalan sebuah model yang baik adalah model dengan kesalahan peramalan yang seminimal mungkin. Karena itu, sebuah model sebelum digunakan seharusnya memenuhi beberapa asumsi, yang biasa disebut asumsi klasik". Dalam penelitian ini uji asumsi klasik yang digunakan: Uji Normalitas, Uji Multikolinearitas, Uji Autokorelasi, dan Uji Heterokedastisitas.

\section{Analisis Kuantitatif}

Analisis kuantitatif adalah penelitian untuk menilai kondisi dari nilai pengaruh, dan signifikansi pengaruh tersebut. Dalam penelitian ini analisis kuantitatif yang digunakan: Analisis Regresi Linier Sederhana, Linier Berganda, Analisis Koefisien Korelasi, Analisis Koefisien Determinasi, Pengujian Hipotesis.

\section{Hasil Penelitian dan Pembahasan Uji Validitas Instrumen}

Tabel 4. Hasil Uji Validitas Kepemimpinan $\left(\mathrm{X}_{1}\right)$

\begin{tabular}{|c|c|c|c|}
\hline \multirow{2}{*}{ Pernyataan } & \multicolumn{3}{|c|}{ Kepemimpinan (X1) } \\
\cline { 2 - 4 } & r hitung & r tabel & Keterangan \\
\hline 1 & 0.404 & 0.227 & Valid \\
\hline 2 & 0.501 & 0.227 & Valid \\
\hline 3 & 0.514 & 0.227 & Valid \\
\hline 4 & 0.557 & 0.227 & Valid \\
\hline 5 & 0,531 & 0.227 & Valid \\
\hline 6 & 0.432 & 0.227 & Valid \\
\hline 7 & 0.411 & 0.227 & Valid \\
\hline 8 & 0,484 & 0.227 & Valid \\
\hline 9 & 0,511 & 0.227 & Valid \\
\hline 10 & 0,557 & 0.227 & Valid \\
\hline 11 & 0,502 & 0.227 & Valid \\
\hline 12 & 0,590 & 0.227 & Valid \\
\hline 13 & 0,523 & 0.227 & Valid \\
\hline 14 & 0,455 & 0.227 & Valid \\
\hline 15 & 0,529 & 0.227 & Valid \\
\hline 16 & 0,408 & 0.227 & Valid \\
\hline 17 & 0,436 & 0.227 & Valid \\
\hline 18 & 0,459 & 0.227 & Valid \\
\hline
\end{tabular}

Sumber pengolahan Data SPSS 22, (2020) 
Tabel 5. Hasil Uji Validitas Motivasi Kerja $\left(\mathrm{X}_{2}\right)$

\begin{tabular}{|c|c|c|c|}
\hline \multirow{2}{*}{ Pernyataan } & \multicolumn{3}{|c|}{ Motivasi Kerja (X2) } \\
\cline { 2 - 4 } & r hitung & r tabel & Keterangan \\
\hline 1 & 0.487 & 0.227 & Valid \\
\hline 2 & 0.856 & 0.227 & Valid \\
\hline 3 & 0.824 & 0.227 & Valid \\
\hline 4 & 0.847 & 0.227 & Valid \\
\hline 5 & 0.813 & 0.227 & Valid \\
\hline 6 & 0.436 & 0.227 & Valid \\
\hline 7 & 0,574 & 0.227 & Valid \\
\hline 8 & 0,503 & 0.227 & Valid \\
\hline 9 & 0,476 & 0.227 & Valid \\
\hline 10 & 0,480 & 0.227 & Valid \\
\hline 11 & 0,652 & 0.227 & Valid \\
\hline 12 & 0,512 & 0.227 & Valid \\
\hline 13 & 0,671 & 0.227 & Valid \\
\hline 14 & 0,701 & 0.227 & Valid \\
\hline 15 & 0,852 & 0.227 & Valid \\
\hline
\end{tabular}

Sumber pengolahan Data SPSS 22, (2020)

Tabel 6. Hasil Uji Validitas Variabel Kinerja (Y)

\begin{tabular}{|c|c|c|c|}
\hline \multirow{2}{*}{ Pernyataan } & \multicolumn{3}{|c|}{ Kinerja (Y) } \\
\cline { 2 - 4 } & r hitung & r tabel & Keterangan \\
\hline 1 & 0.571 & 0.227 & Valid \\
\hline 2 & 0.434 & 0.227 & Valid \\
\hline 3 & 0.659 & 0.227 & Valid \\
\hline 4 & 0.634 & 0.227 & Valid \\
\hline 5 & 0.579 & 0.227 & Valid \\
\hline 6 & 0.589 & 0.227 & Valid \\
\hline 7 & 0,541 & 0.227 & Valid \\
\hline 8 & 0,703 & 0.227 & Valid \\
\hline 9 & 0,717 & 0.227 & Valid \\
\hline 10 & 0,605 & 0.227 & Valid \\
\hline 11 & 0,495 & 0.227 & Valid \\
\hline 12 & 0,526 & 0.227 & Valid \\
\hline 13 & 0,620 & 0.227 & Valid \\
\hline 14 & 0,529 & 0.227 & Valid \\
\hline 15 & 0,552 & 0.227 & Valid \\
\hline
\end{tabular}

Sumber pengolahan Data SPSS 22, (2020)

Berdasarkan data tabel di atas, variabel $X_{1}, X_{2}$ dan $Y$ diperoleh nilai $r$ hitung $>r$ tabel (0.254), dengan demikian maka semua item kuesioner dinyatakan valid. Untuk itu kuesioner yang digunakan layak untuk diolah sebagai data penelitian.

\section{Uji Reliabilitas Instrumen}

Tabel 7. Hasil Uji Reliabilitas

\begin{tabular}{|l|c|c|c|}
\hline \multicolumn{1}{|c|}{ Variabel } & Cronbatch Alpha & $\begin{array}{c}\text { Standar Cronbatch } \\
\text { Alpha }\end{array}$ & Keputusan \\
\hline Kepemimpinan (X1) & 0.804 & 0.600 & Reliabel \\
\hline Motivasi (X2) & 0.912 & 0.600 & Reliabel \\
\hline Kinerja Pegawai (Y) & 0.862 & 0.600 & Reliabel \\
\hline
\end{tabular}

Sumber pengolahan Data SPSS 22, (2020) 
Berdasarkan hasil pengujian pada tabel di atas, menunjukkan bahwa variabel kepemimpinan $\left(\mathrm{X}_{1}\right)$, motivasi $\left(\mathrm{X}_{2}\right)$ dan kinerja pegawai $(\mathrm{Y})$ dinyatakan reliabel, hal itu dibuktikan dengan masing-masing variabel memiliki nilai Chronbath Alpha lebih besar dari 0,600

\section{Uji Asumsi Klasik Uji Normalitas}

Tabel 8. Hasil Uji Kolmogorov-Simirnov Test

\begin{tabular}{|ll|r|}
\hline & & \multicolumn{2}{|c|}{ Unstandardized Residual } \\
\hline $\mathrm{N}$ & & 76 \\
Normal & Mean & 0 \\
Parameters & Std. Deviation & 4,98204224 \\
Most Extreme & Absolute & 0,081 \\
Differences & Positive & 0,055 \\
& Negative & $-0,081$ \\
Test Statistic & & 0,081 \\
Asymp. Sig. (2-tailed) & $.200^{\mathrm{c}, \mathrm{d}}$ \\
\hline
\end{tabular}

Sumber pengolahan Data SPSS 22, (2020)

Berdasarkan uji normalitas dengan Kolmogorov-Smirnov Test diperoleh nilai Asymp.sig. sebesar 0,200 lebih besar dari 0,05 maka dapat disimpulkan data berdistribusi normal. Untuk mengetahui kriterianya yaitu dengan membandingkan distribusi kumulatif dari distribusi normal. Ditribusi normal akan membentuk suatu garis lurus diagonalnya.

\section{Uji Multikolinearitas}

Tabel 9. Hasil Uji Multikolinearitas

\begin{tabular}{|c|c|c|}
\hline \multirow{2}{*}{ Model } & \multicolumn{2}{|c|}{ Collinearity Statistics } \\
\cline { 2 - 3 } & Tolerance & VIF \\
\hline Kepemimpinan (X1) & 0,56 & 1,786 \\
\hline Motivasi Kerja(X2) & 0,56 & 1,786 \\
\hline
\end{tabular}

Sumber pengolahan Data SPSS 22, (2020)

Dari hasil data di atas dapat disimpulkan bahwa data yang ada tidak terjadi gejala multikolonieritas antara masing - masing variabel independen, yaitu dengan melihat nilai tolerance danVIF. Nilai tolerance yang diperoleh 0,560 dan nilai VIF yang diperoleh 1,786. Karena data di atas menunjukan bahwa nilai tolerance lebih besar dari 0,10 dan nilai VIF lebih kecil dari 10,00 keadaan seperti itu membuktikan tidak terjadinya multikolonieritas.

\section{Uji Heterokedastisitas}

Jika ada pola tertentu, seperti titik-titik (point-point) yang ada membentuk suatu pola tertentu yang teratur (bergelombang, melebar, kemudian menyempit) maka terjadi heteroskedastisatas. Jika ada pola yang jelas, serta titik-titik menyebar diatas dan dibawah angka 0 pada sumbu $Y$, maka tidak terjadi heteroskedastisitas.

Uji heteroskedastisitas dalam penelitian ini dilakukan dengan alat bantuan SPSS. Adapun grafik plot dalam uji heterokdastisitas dapat dilihat pada gambar dibawah ini: 


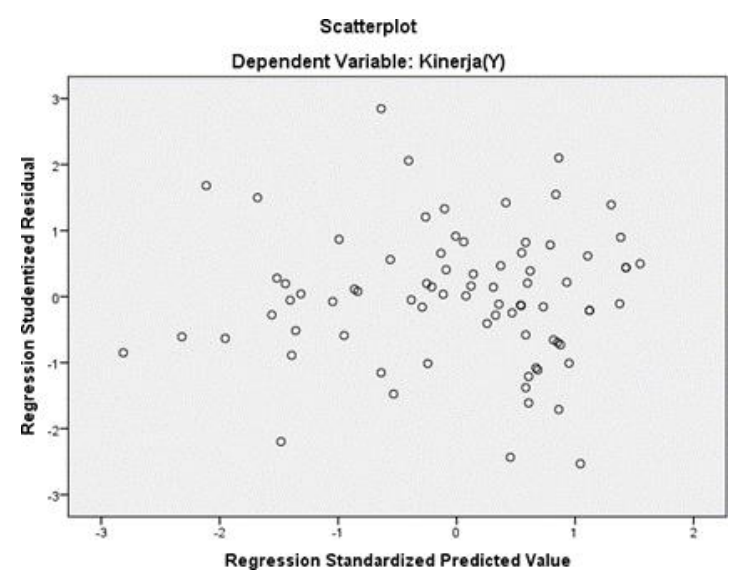

Sumber pengolahan Data SPSS 22, (2020)

Gambar 1. Hasil Heteroskedastisitas

Analisis Koefisien Korelasi

Tabel 10. Hasil Uji Analisis Regresi Koefisien Korelasi

\begin{tabular}{|ll|r|r|r|}
\hline & & $\begin{array}{r}\text { Kepemimpinan } \\
(\mathrm{X} 1)\end{array}$ & $\begin{array}{r}\text { Motivasi Kerja } \\
(\mathrm{X} 2)\end{array}$ & \multicolumn{2}{c|}{$\begin{array}{c}\text { Kinerja } \\
(\mathrm{Y})\end{array}$} \\
\hline Kepemimpinan (X1) & Pearson Correlation & 1 &, $663^{* *}$ &, $730^{* *}$ \\
& Sig. (2-tailed) & &, 000 &, 000 \\
& $\mathrm{~N}$ & 76 & 76 & 76 \\
\hline Motivasi Kerja (X2) & Pearson Correlation &, $663^{* *}$ & 1 &, $646^{* *}$ \\
& Sig. (2-tailed) &, 000 & 76 &, 000 \\
& $\mathrm{~N}$ & 76 & 76 & 76 \\
\hline Kinerja (Y) & Pearson Correlation &, $730^{* *}$ &, $646^{* *}$ & 1 \\
& Sig. (2-tailed) &, 000 &, 000 & \\
& $\mathrm{~N}$ & 76 & 76 & 76 \\
\hline
\end{tabular}

Sumber pengolahan Data SPSS 22, (2020)

Dari hasil koefisien korelasi dari 76 kuesioner dihasilkan pengaruh Kepemimpinan sebesar 0,730 dan rtabel sebesar 0,279 dikatakan valid apabila rhitung > rtabel,jika 0,730 $>0,279$ dan Motivasi Kerja sebesar 0,646, dikatakan valid apabila rhitung > rtabel, jika 0,646> 0,279, maka disimpulkan bahwa Kepemimpinan (X1) dan Motivasi Kerja (X2) berpengaruh terhadap Kinerja Pegawai (Y).

\section{Regresi Linier Sederhana}

Tabel 11. Hasil Uji Regresi Linear Sederhana Variabel Kepemimpinan $\left(X_{1}\right)$ Terhadap Kinerja Pegawai (Y)

\begin{tabular}{|ll|r|r|r|r|r|}
\hline \multirow{2}{*}{ Model } & \multicolumn{2}{|c|}{$\begin{array}{c}\text { Unstandardized } \\
\text { Coefficients }\end{array}$} & \multicolumn{1}{c|}{$\begin{array}{c}\text { Standardized } \\
\text { Coefficients }\end{array}$} & \multirow{2}{*}{$\mathrm{T}$} & \multirow{2}{*}{ Sig. } \\
\cline { 3 - 5 } & \multicolumn{1}{|c|}{ B } & Std. Error & \multicolumn{1}{c|}{ Beta } & & \\
\hline 1 & (Constant) & 4,339 & 5,51 & & 0,79 & .000 \\
& Kepemimpinan $\left(\mathrm{X}_{1}\right)$ & 0,561 & 0,104 & 0,538 & 5,38 & .000 \\
\hline
\end{tabular}

Sumber pengolahan Data SPSS 22, (2020) 
Tabel 12. Hasil Uji Regresi Linear Sederhana Variabel Motivasi Kerja $\left(X_{2}\right)$ Terhadap Kinerja Pegawai (Y)

\begin{tabular}{|l|r|r|r|r|r|}
\hline \multirow{2}{*}{ Model } & \multicolumn{2}{|c|}{$\begin{array}{c}\text { Unstandardized } \\
\text { Coefficients }\end{array}$} & $\begin{array}{c}\text { Standardized } \\
\text { Coefficients }\end{array}$ & \multirow{2}{*}{$\mathrm{t}$} & \multirow{2}{*}{ Sig. } \\
\cline { 2 - 4 } & \multicolumn{1}{|c|}{$\mathrm{B}$} & Std. Error & \multicolumn{1}{c|}{ Beta } & & \\
\hline (Constant) & 4,339 & 5,51 & & 0,787 & .000 \\
Motivasi Kerja $\left(\mathrm{X}_{2}\right)$ & 0,253 & 0.088 & 0,289 & 2,88 & .000 \\
\hline
\end{tabular}

Sumber pengolahan Data SPSS 22, (2020)

Nilai 4,339 merupakan nilai konstanta bernilai positif yang menunjukan bahwa variabel dependen yaitu Kinerja $(Y)$ memiliki hubungan yang positif dengan variabel independen Kepemimpinan dan Motivasi Kerja, sedangkan 0,561 merupakan koefisien pengaruh variabel independen Kepemimpinan $\left(\mathrm{X}_{1}\right)$ terhadap variabel dependen Kinerja Karyawan (Y). Berarti bahwa Kepemimpinan dan Motivasi Kerja mempengaruhi atau mengakibatkan terjadinya peningkatan yang signifikan terhadap Kinerja Pegawai. Dari hasil output diatas,Adapun bentuk persaman dari hasil perhitungan dengan melihat dalam tabel 1112 dan persamaan berikut dapat dituliskan sebagai berikut :

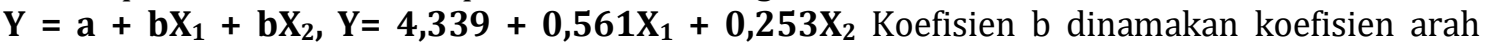
regresi dan menyatakan perubahan rata-rata variabel $Y$ untuk setiap perubahan variabel $X$ sebesar satu kesatuan. Perubahan ini merupakan pertambahan bila $\mathrm{b}$ bernilai positif dan penurunan bila b bernilai negative.

Artinya :

1) Konstanta $=4,339$

Artinya, meski tidak ada pengaruh dari variabel motivasi kerja para pegawai tetap memiliki kinerja sebesar 4,33.

2) Koefisien Regresi $(\mathrm{Y})=0.561$ dan 0,253

Merupakan nilai koefisien regresi variabel Kepemimpinan (X1) dan Motivasi Kerja (X2) terhadap variabel Kinerja Pegawai(Y), artinya jika variabel Kepemimpinan (X1) dan Motivasi Kerja (X2) meningkat satu kesatuan, maka Kinerja Pegawai (Y) akan mengalami kenaikan sebesar 0.561 dan 0,253

\section{Pembahasan Penelitian}

Berdasarkan hasil penelitian, menunjukkan bahwa kepemimpinan $\left(\mathrm{X}_{1}\right)$ dan motivasi $\left(\mathrm{X}_{2}\right)$ berpengaruh positif terhadap kinerja pegawai berdasarkan hasil perhitungan SPSS 22 diperoleh nilai F-hitung $=51,649$ dengan signifikan dengan nilai $\mathrm{F}$ sebesar 0.000. Dengan menggunakan tingkatsignifikan 0.05 maka nilai tabel dengan $\mathrm{dk}=\mathrm{n}-\mathrm{k}(76-2=74)$ diperoleh Ftabel 3,12 sebesar tingkat signifikan 0.000 Nilai signifikansi tersebut masih berada dibawah nilai signifikansi yang ditetapkan yaitu 0.05 sehingga dapat disimpulkan bahwa Kepemimpinan dan Motivasi Kerja berpengaruh positif dan signifikan terhadap Kinerja Pegawai dengan persamaan garis regresi adalah. $Y=4,339+0,561 \mathrm{X} 1+0,253 \mathrm{X} 2$.

\section{Kesimpulan}

Berdasarkan hasil perhitungan Regresi diperoleh nilai t-hitung variabel Kepemimpinan, dimana t-hitung sebesar 5,377 dengan signifikan $\alpha=0,000$ sedangkan ttabel sebesar 1,990, maka diperoleh maka $t$ hitung $>t$ tabel dan $t s i g<0,05$ atau 5,337 $>1,990$ dan $0,000<0,05$, hal ini berarti bahwa Kepemimpinan secara komprehensif berpengaruh terhadap Kinerja Pegawai karena nilai signifikan dibawah 0,05 dengan demikian dapat disimpulkan bahwa Kepemimpinan berpengaruh positif dan signifikan terhadap Kinerja Pegawai. Berdasarkan hasil perhitungan Regresi diperoleh nilai thitung variabel Motivasi Kerja, dimana thitung sebesar 2,887 dengan signifikan $\alpha=0,005$ sedangkan ttabel sebesar 1,990, maka diperoleh maka $t$ hitung $>t$ tabel dan tsig $<0,05$ atau 2,887 $>1,990$ dan $0,005<0,05$, hal ini 
berarti bahwa Motivasi Kerja secara parsial berpengaruh terhadap Kinerja Pegawai karena nilai signifikan dibawah 0,05 dengan demikian dapat disimpulkan bahwa Motivasi Kerja berpengaruh positif dan signifikan terhadap Kinerja Pegawai.

Berdasarkan hasil pengujian pengaruh Kepemimpinanl dan Motivasi Kerja, secara bersama-sama memiliki pengaruh positif dan signifikan terhadap Kinerja Pegawai. Berdasarkan hasil perhitungan SPSS 22 diperoleh nilai F-hitung $=$ 51,649 dengan signifikan dengan nilai $\mathrm{F}$ sebesar 0.000 . Dengan menggunakan tingkat signifikan 0.05 maka nilai tabel dengan $\mathrm{dk}=\mathrm{n}-\mathrm{k}(76-2=74)$ diperoleh Ftabel 3,12 sebesar tingkat signifikan 0.000 Nilai signifikansi tersebut masih berada dibawah nilai signifikansi yang ditetapkan yaitu 0.05 sehingga dapat disimpulkan bahwa Kepemimpinan dan Motivasi Kerja berpengaruh positif dan signifikan terhadap Kinerja Pegawai dengan persamaan garis regresi adalah ; $\mathbf{Y = 4 , 3 3 9 +}$ 0,561 X1 + 0,253 X2.

\section{Daftar Pustaka}

Anwar Prabu Mangkunegara (2013). Evaluasi Kinerja Sumber Daya Manusia (SDM). PT Refika Aditama, Bandung.

Didi Sunardi, (2020). Pengaruh Gaya Kepemimpinan dan Jabatan Fungsional Perekayasa Terhadap Kinerja Pegawai Pada Balai Besar Teknologi Aerodinamika, Aeroelastika, Aeroakustika BPPT, Setu Tangerang Selatan. Jurnal Madani , Vol.3 No. 1.

Edy, Sutrisno. (2012). Manajemen Sumber Daya Manusia. Jakarta: Kencana.

Guruh Dwi Pratama, (2020). Pengaruh Gaya Kepemimpinan dan Motivasi kerja Terhadap Kinerja Karyawan Pada PT. Garuda Karya Mandiri. Jurnal Efektif, Vol 2 No. 2.

Hadari Nawawi (2016), Manajemen Sumber Daya Manusia Untuk Bisnis Yang Kompetitif, Gajah Mada University Pres, Yogyakarta

Kartono Kartini. (2016), Pemimpin dan Kepeimpinan, Apakh Pemimpin Abnormal Itu?, PT. Raja Grafindo Persada, Jakarta.

Malayu S.P Hasibuan. (2013). Manajemen Sumber Daya Manusia Perusahaan. Bumi Aksara, Jakarta.

Miftah Thoha, (2017), Manajemen Sumber Daya Manusia (MSDM), Edisi 2 PT. Raja Grafindo Jakarta.

Rahmad Setiawan, (2019). Pengaruh Kepemimpinan Tranformasional dan Motivasi Kerja Terhadap Kinerja Karyawan Pada PT. Tirta Varia Intipratama Daat Mogot Jakarta Barat. Jurnal Kreatif, Vol.7 No. 2.

Rivai Veithzal, (2015), Manajemen Sumber Daya Manusia, untuk Perusahaan. PT. Rajagrafindo Persada, Jakarta.

Rivai Veithzal, (2017).Kepemimpinan dan Perilaku Organisasi. PT. Rajagrafindo Persada, Jakarta.

Serdamayanti (2017). Manajemen Sumber Daya Manusia Reformasi Birokrasi dan Manajemen Pegawai Negeri Sipil. PT Refika Aditama, Bandung

Sondang P Siagian (2015), Manajemen Sumber Daya Manusia, Bumi Aksara, Jakarta

Sugiyono (2017). Metode Penelitian Bisnis (Pendekatan kuantitatif, Kualitatif dan R\&D). CV. Alfabeta, Bandung

Wibowo (2017), Manajemen Kinerja, Edisi Kedua, PT. Raja Grafindo Persada, Jakarta. 